\title{
Technical Guidelines for Disinfection of Special Sites for COVID-19
}

\author{
Chinese Center for Disease Control and Prevention
}

\section{PRINCIPLES OF DISINFECTION}

\section{Determination of Scope and Objects}

One should determine the scope, the objects for disinfection, and the timing of disinfection based on an epidemiological investigation risk assessment. Places where patients and asymptomatic infected individuals have stayed, such as homes, medical institutions, isolation wards, transfer vehicles, etc., should carry out concurrent disinfection and should have a terminal disinfection after discharge or death of a patient; for asymptomatic infected individuals, a terminal disinfection should be done after their nucleic acid test results turn negative.

\section{Selection of Disinfection Methods}

Medical institutions should strive to use disposable diagnostic supplies as much as possible. For nondisposables, pressurized steam sterilization is preferred, but heat-sensitive items can be disinfected or sterilized with chemical disinfectants or low-temperature sterilization equipment.

The environmental subject surface can be disinfected by wiping, spraying, or soaking with chlorinated disinfectants, chlorine dioxide, or other chemical disinfectants.

For hand and skin disinfection, an effective disinfectant such as povidone-iodine and hydrogen peroxide or other alcohol-based hand rub should be used.

For indoor air disinfection, one can choose disinfection sprays such as peracetic acid, chlorine dioxide, and hydrogen peroxide.

All disinfection products must comply with national health department management requirements.

\section{DISINFECTION MEASURES}

\section{Concurrent Disinfection}

Concurrent disinfection refers to the timely disinfection of items and places potentially contaminated by patients or asymptomatic infected persons. Places where patients have stayed, such as homes, isolation wards of medical institutions, medical observation sites, transfer vehicles, as well as the contaminated items and waste from patients should carry out concurrent disinfection. For disinfection methods, refer to the section on terminal disinfection. Do not use spray disinfection when there are people in the room. Ventilation (natural or mechanical ventilation) in isolation rooms should be used to maintain adequate indoor air circulation. Rooms should be ventilated 2 to 3 times a day for at least 30 minutes each time.

If negative pressure isolation wards are available, patients should be placed in negative pressure isolation wards of healthcare facilities; patients with suspected cases should be isolated in single rooms; those with confirmed cases can occupy the same room. Nonnegative pressure isolation wards should be well ventilated through natural or mechanical ventilation; alternatively, air disinfecting machines with circulating air can be used to disinfect air. Ultraviolet light can also be used for air disinfection in unoccupied areas. When using ultraviolet light, exposure times can be extended to more than one hour. Medical staff and companions should wash and disinfect their hands after diagnosis, treatment, or nursing procedures.

\section{Terminal Disinfection}

Terminal disinfection refers to the thorough disinfection after a potential source of infection has left a relevant site. The goal of terminal disinfection is to ensure that disinfected places and objects are made pathogen-free. Terminal disinfection targets include patients and asymptomatic infected persons' excretions and secretions (blood, secretions, vomitus, feces, etc.) and places potentially contaminated by such wastes. It is not necessary to disinfect the outdoor environment (including the air) on a large scale. Terminal disinfection is not needed for places where asymptomatic infected persons have temporarily stayed, provided there is no waste or other residue from their stay.

\section{Patient Homes}

After a patient is hospitalized or dies, or an 
asymptomatic infected person's nucleic acid test results turn negative, terminal disinfection should be carried out targeting surfaces of floors, walls, table, chairs, and other furniture; door handles, tableware, and drinkware; clothes, bedding, and other daily necessities; toys; and bathrooms including toilets.

\section{Vehicles}

Terminal disinfection should be performed after patients and asymptomatic infected persons exit vehicles. Disinfection should be carried out and include surfaces of cabins, seats, sleepers, tableware and drinkware, textiles such as bedding, excreta, vomitus, items, places contaminated by excreta and vomitus, and toilets in trains and aircraft.

\section{Medical Institutions}

Fever outpatient clinics and infectious disease outpatient clinics should have terminal disinfection performed at the end of every working day. Isolation wards should perform terminal disinfection after patient discharge or death or after nucleic acid testing of asymptomatic infected persons turns negative. Terminal disinfection should include floors, walls, surface of tables, chairs, bedside tables, bedsteads, patients' clothes and bedding, other daily necessities, medical supplies, and indoor air.

\section{Terminal Disinfection Procedures}

The terminal disinfection procedure is performed in accordance with Appendix A of the General Principles of Disinfection of Epidemic Focus (GB 19193-2015). On-site disinfection personnel should use individual protection when preparing and using chemical disinfectants.

\section{DISINFECTION OF COMMONLY CONTAMINATED OBJECTS}

\section{Indoor Air}

For terminal disinfection of indoor air in venues such as households and isolation wards of medical institutions, one can refer to the "Management Specifications of Air Cleaning Technique in Hospitals" (WS/T 368-2012). Peracetic acid, chlorine dioxide, hydrogen peroxide, and other disinfectants can be selected to disinfect indoor areas (while unoccupied) by ultra-low volume spray.

\section{Contaminants (Blood, Secretions, Vomitus, etc.)}

Small amounts of waste can be carefully removed by using disposable absorbent materials (such as gauze or wipes) and dipped in 5,000-10,000 $\mathrm{mg} / \mathrm{L}$ chlorinecontaining disinfectant. Alternatively, disinfecting with wet wipes/dry wipes that are able to achieve high-level disinfection is acceptable.

Large volumes of waste should be completely covered with disinfectant powder or bleach powder containing water-absorbing ingredients or fully covered with disposable water-absorbing materials that can achieve high-level disinfection. A sufficient amount of 5,000-10,000 mg/L chlorine-containing disinfectant (or disinfected dry towels) should be poured on the water-absorbing materials for 30 minutes followed by careful removal of the waste. One should avoid contact with waste during removal. Resulting disinfected waste should be properly disposed of as medical waste.

Patients' secretions and vomitus should be collected in a specialized container and should be soaked for two hours with $20,000 \mathrm{mg} / \mathrm{L}$ chlorine-containing disinfectant using a ratio of $1: 2$ for waste to disinfectant.

After removal of waste, surfaces of the contaminated objects should be disinfected. The container containing waste can be soaked with a $5,000 \mathrm{mg} / \mathrm{L}$ chlorinecontaining disinfectant for 30 minutes before being cleaned.

\section{Feces and Sewage}

Independent septic tanks should be disinfected before their materials enter the municipal drainage pipe network; chlorine-containing disinfectant should be added regularly, and chlorine-containing disinfectant should be added into the tank. Initially, the effective chlorine level should be at least $40 \mathrm{mg} / \mathrm{L}$ and total residual chlorine should be $10 \mathrm{mg} / \mathrm{L}$ after 1.5 hours of disinfection. Disinfected sewage should meet the Discharge standard of water pollutants from medical organizations (GB18466-2005).

In the absence of a separate septic tank, special containers should be used to collect, disinfect, and dispose of feces. Chlorine-containing disinfectant with effective chlorine concentrations of $20,000 \mathrm{mg} / \mathrm{L}$ should be used to soak excrement for 2 hours with an excrement to disinfectant ratio of $1: 2$. If there is a large amount of diluted excrement, 70\%-80\% effective chlorine concentration bleaching powder should be applied, and the slurry should be thoroughly mixed for 2 hours with an excrement to disinfectant ratio of $20: 1$. 


\section{Floors and Walls}

If there are visible contaminants, the contaminants should be completely removed before disinfection. When there are no visible contaminants, one can use $1,000 \mathrm{mg} / \mathrm{L}$ of chlorine containing disinfectant or $500 \mathrm{mg} / \mathrm{L}$ chlorine dioxide to wipe or spray the floors and walls. Floors should be sprayed with disinfectant once from outside to inside with a volume of 100-300 $\mathrm{mL} / \mathrm{m}^{2}$. Following indoor disinfection, the floor should be sprayed once more from the inside out. Disinfection time should be no less than 30 minutes.

\section{Subject Surfaces}

When there are visible contaminants on the surface of diagnosis and treatment equipment such as bed rails, bedside tables, furniture, door handles, or household items, the contaminants should be completely removed before disinfection. When there are no visible contaminants, $1,000 \mathrm{mg} / \mathrm{L}$ of chlorine-containing disinfectant or $500 \mathrm{mg} / \mathrm{L}$ of chlorine dioxide can be used for spraying, wiping, and soaking. After 30 minutes of disinfection, surfaces can be wiped clean with water.

\section{Clothing, Bedding and Other Textiles}

Aerosols should be avoided during collection, and it is recommended that textiles be centrally incinerated as medical waste. When there are no visible contaminants and if the textiles need to be reused, they can be disinfected with circulating steam or by boiling for 30 minutes. Alternatively, $500 \mathrm{mg} / \mathrm{L}$ of chlorinecontaining disinfectant can be used to soak contaminated textiles for 30 minutes prior to standard washing. Alternatively, they can be washed in a washing machine in a water-soluble packaging bag, washed, and then disinfected for 30 minutes, with an effective chlorine content maintained at $500 \mathrm{mg} / \mathrm{L}$. Delicate or valuable clothing can be disinfected using ethylene oxide.

\section{Hand Hygiene}

Personnel participating in field work should always use proper hand hygiene practices. An effective alcohol or alcohol compound-based hand rub can be used. Hands can also be directly wiped with $75 \%$ ethanol solutions. Individuals allergic to alcohol can choose an effective non-alcohol hand antiseptic agent such as quaternary ammonium disinfectant; under special circumstances, a 3\% hydrogen peroxide solution disinfectant, $0.5 \%$ povidone-iodine, or $0.05 \%$ chlorine-containing disinfectant can be used to wipe or soak hands, using an appropriately prolonged disinfection time. One should wash hands with liquid soap and running water before disinfection when there are visible contaminants.

\section{Skin and Mucous Membranes}

When skin is contaminated, the contaminants should be removed immediately, and the skin should be wiped for at least 3 minutes with a disposable absorbent material dipped with $0.5 \%$ povidone-iodine or hydrogen peroxide and washed with water. Mucous membranes should be washed with a large amount of physiologic saline or rinsed and disinfected with $0.05 \%$ povidone-iodine.

\section{Tableware and Drinkware}

After tableware or drinkware is cleared of food residue, it should be boiled and disinfected for 30 minutes or immersed in a chlorine-containing disinfectant with an effective chlorine of $500 \mathrm{mg} / \mathrm{L}$ and soaked for 30 minutes before being rinsed with water.

\section{Transported and Transferred Tools}

The degree of contamination should be evaluated. When there are visible contaminants in trains, cars, or ships, one should first use disposable absorbent materials dipped with 5,000-10,000 mg/L chlorinecontaining disinfectant (or by using disinfectant wipes/dry towel that can achieve high-level disinfection) to completely remove the contaminants, followed by spraying or wiping the area with $1,000 \mathrm{mg} / \mathrm{L}$ chlorine-containing disinfectant or 500 $\mathrm{mg} / \mathrm{L}$ chlorine dioxide and wiping with clean water after 30 minutes of disinfection. When disinfecting aircraft cabins, disinfectant types and dosages should be selected in accordance with the relevant regulations of the Civil Aviation Administration of China. Fabrics, cushions, pillows, and sheets are recommended to be collected and managed centrally as medical waste.

\section{Domestic Wastes from Patients}

Waste from patients should treated as medical waste.

\section{Medical Waste}

The disposal of medical waste should follow the requirements of the Medical Waste Management Regulations and the Medical Waste Management Measures of Medical Institutions. Waste should be collected, packed, and sealed through standard use of double-layered yellow medical waste collection bags; standard medical waste disposal procedures are to be followed. 


\section{Corpse}

After death of a patient, one should minimize movement and handling of the corpse leaving it to be promptly handled by trained staff under strict protection procedures. Cotton balls or gauze with $3,000-5,000 \mathrm{mg} / \mathrm{L}$ chlorine-containing disinfectant or $0.5 \%$ peracetic acid should be used to fill the patient's mouth, nose, ears, anus, trachea opening, and other open channels or wounds. The body should be wrapped with a double-layer cloth soaked with disinfectant, placed in a double-layer body bag, and sent directly by a special vehicle from the civil affairs department to the designated place for cremation as soon as possible.

\section{Precautions}

On-site disinfection work should be conducted in a timely manner by relevant organizations under the guidance of the local disease prevention and control agency or directly by the local disease prevention and control agency responsible for disinfection. Medical institution periodic disinfection and terminal disinfection should be arranged by the medical institutions with technical guidance from the disease control agency. Non-professionals should receive professional training from local disease prevention and control agencies before starting disinfection so that they can adopt correct disinfection methods and have thorough personal protection.

\section{EVALUATION OF DISINFECTION}

When necessary, the effectiveness of disinfecting object surfaces, air, and hands should be evaluated in a timely manner by relevant laboratory personnel eligible to conduct such testing.

\section{Object Surfaces}

Surfaces of objects before and after disinfection should be sampled according to Hygienic Standard for Disinfection in Hospitals (GB 15982-2012), with the sampling solution after disinfection being the corresponding neutralizer.

Evaluation of disinfection is generally based on absence of natural bacteria. If necessary, indicator bacteria can also be used to evaluate disinfection. Resilience of the indicator bacteria should be equal to or greater than resilience of the existing pathogens. When using natural bacteria as an indicator, the kill rate of bacteria on the object should be $\geq 90 \%$ after disinfection to be considered as qualified (passing). When using indicator bacteria, the kill rate should be $\geq 99.9 \%$ after disinfection to be considered as qualified.

\section{Indoor Air}

Air, before and after disinfection, should be sampled according to Hygienic Standard for Disinfection in Hospitals (GB 5982-2012). Air sampling plates should contain the corresponding neutralizing agent after disinfection. The kill rate of natural bacteria in the air after disinfection should be $\geq 90 \%$ to be considered as qualified (passing).

\section{Staff Hands}

Pre- and post-disinfected hands should be sampled according to the Appendix A under Hygienic Standard for Disinfection in Hospitals (GB 15982-2012) with the sampling solution for post disinfected hands being the corresponding neutralizer. The kill rate of natural bacteria on the hand after the disinfection should be $\geq$ $90 \%$ to be considered as qualified (passing).

\section{Disinfection of Hospital Sewage}

Evaluation should be conducted according to the relevant provisions in Water Pollutant Discharge Standards for Medical Institutions (GB 18466-2005).

Acknowlegement: China CDC Weekly would like to thank Xijuan Fu of the WHO China Office, Lance Rodewald and Liping Wang of China CDC, and Baoying Zhang and Jin Shen of National Institute of Environment Health, China CDC for their contributions in translating and editing this document (1).

This Chinese document written by experts in China CDC Key Places Protection and Disinfection Technology Group for COVID-19 Emergency Response, including Liubo Zhang, Jin Shen, Hongyang Duan, Baoying Zhang, Chen Liang, and Huihui Sun of National Institute of Environment Health, China CDC.

doi: $10.46234 / \mathrm{ccdcw} 2020.086$

Submitted: March 10, 2020; Accepted: March 12, 2020

\section{REFERENCES}

1. Chinese Center for Disease Control and Prevention. Technical documents forCOVID-19 prevention and control. http://www.chinacdc. cn/jkzt/crb/zl/szkb_11803/jszl_11815/202003/t20200309_214241.html. [2020-3-9]. (In Chinese). 